\title{
Comparison of local Salmonella pullorum antigen with imported product in whole blood agglutination test
}

\author{
Priyani Medewewa, Madalagama A. R. Priyantha, Gnana Gunawardana, \\ A. A. Vipulasiri, Nilukshi Liyanagunawardana \\ Bacteriology Division, \\ Veterinary Research Institute, PO Box 28, Peradeniya, Sri Lanka. \\ Corresponding author: Madalagama A. R. Priyantha, e-mail: appuhami1974@yahoo.com \\ Received: 22-02-2012, Accepted: 04-03-2012, Published Online: 19-06-2012 \\ doi: $10.5455 /$ veworld.2012.546-548
}

\begin{abstract}
Background: Salmonellosis is considered as one of the most important diseases in poultry as it causes devastating losses in chicken industry. Proper identification of the infected and carrier birds is required to control the disease among chickens. In field situation whole blood agglutination test is performed in order to identify carriers of Pullorum and Fowl typhoid particularly, in breeder operations. In this test, serum antibodies are detected by using a specially made antigen for this purpose. In Sri Lanka, three antigen products are used commonly in whole blood agglutination test.

Aim: This study was carried out to compare these two locally available $S$. Pullorum antigen products and to determine any difference in the efficacy.

Materials and Methods: "Shaver Brown" commercial layer birds (70 in number) were used in the experiment. Birds were inoculated orally with $1.8 \times 10^{9} \mathrm{cfu} / \mathrm{ml}$ of $S$. Pullorum at 16 weeks age. After Three weeks post inoculation, blood was collected from each bird and Whole blood agglutination test was performed using both antigen products. Fifteen (15) inoculated hens were selected randomly and cloacal swabs were cultured on cultured Agar on same day of serum collected.

Results: In this study, there was no significant difference observed between two antigens to detect carrier birds by whole blood agglutination test. Salmonella was not isolated from cloacal swabs since no observed excretion of Salmonella Pullorum through faces. All cloacal swabs gave negative results, when cultured on artificial Agar.

Conclusion: Both antigen can be used effectively to detect carrier birds under the control program in country.

Keywords: Cloacal Swabs, Layer birds, Shaver Brown, Whole blood agglutination test.
\end{abstract}

To cite this article: Medewewa P, Priyantha MAR, Gunawardana G, Vipulasiri AA, Liyanagunawardana N (2012) Comparison of local Salmonella pullorum antigen with imported product in whole blood agglutination test, Vet World, 5(9): 546-548, doi: 10.5455/veworld.2012.546-548

\section{I ntroduction}

The genus Salmonella, of the family Enterobacteriaceae contains over 2400 serotypes which may infect wide range of animals [1]. Since bacteria often excreted in feces, Organisms may be present in water, soil, animal feeds, raw meat, and offal and in vegetable materials [1]. In global contest, Isolations of Salmonellae are reported more often from poultry and its products than rest of the livestock and other animal species in world $[2,3]$.

Chicken is the natural hosts for S. Pullorum and S.Gallinarum [1], infects young chicks at two to three weeks of age[1]. Characteristic lesions include whitish nodules throughout the lungs and focal necrosis of liver and spleen $[1,4,5]$. It was reported in previous studies that a greater percentage of female than male stay as reactors, due to the sequestered nature of local infections of the ovarian follicles [3]. The disease can be transmitted through eggs to the chicks $(6,7)$. However, chronic carriers are the most important reservoirs of the bacterium that transmit to rest of the birds [3,4].

The Pullorum disease can be controlled by continuous eliminating of carrier birds by bloodtesting of potential breeding bird followed by culling [7]. Breeders that test negative produce non-infected eggs later non-infected chicks $(7,8)$. Since $S$. Pullorum and S. Gallinarum possess similar somatic antigens, both have been shown positive reaction during whole blood agglutination test [9]. However, antibodies from live or killed vaccine can be interfered with the testing and prohibited to use in breeder flock, Sri Lanka[7]. The whole blood agglutination test is a simple and less costly test, greatest value when used on a flock basis. $[1,7,9]$. 
Serological prevalence of Salmonella Pullorum is monitored routinely in every breeder farm, Sri Lanka from 16 weeks onwards [7]. Retesting is carried out at intervals of 60-90 days if the flock shows more than $1 \%$ positive reactors that allow in rapid whole blood agglutination test [7]. However, there was believed among farmers that different antigens gathered different results and local antigens are not met up to the standards of imported products. The objective of this study is to compare the reading of WBAT with reputed imported products in order to maintain unique reading through the control program.

\section{Materials and Methods}

Ethical clearance: the ethical clearance for the study was given by the Animal Ethical Review Committee at Veterinary Research Institute, Sri Lanka.

Hens: Shaver Brown layer birds (70) derived from same hatch were used for the study. They were reared at the Veterinary Research Institute, Gannoruwa under deep liter management system.

Antigen products: Two antigens namely, one from Veterinary Research Institute (A) and one of the Imported brand antigen (B)were used in the study, the A was produced by the given standard in the OIE(8).

Salmonella Pullorum cultures: Reference S. Pullorum cultures were used to inoculate experiment hens to crate carrier birds and Cultures was plated on McConkey agar $\left(24 \mathrm{Hour}\right.$ at $\left.37^{\circ} \mathrm{C}\right)$, harvested in normal saline, incubated at $37^{\circ} \mathrm{C}$ for $8-12$ hours.

Experimental design: Sixteen weeks old Salmonella negative birds were used experimentally inoculated with S. Pullorum ( $1 \mathrm{ml}$ dose orally $-1.8 \times 10^{9}$ colony forming unit $/ \mathrm{ml}$ ) and ten hens were included in control group and reared separately. Birds were bled three weeks later from the brachial vein, centrifuged at 1500 rpm for 10 minutes for serum separation. Serum samples allowed to thaw in room temperature for $1 / 2-1$ hour before testing.. Then five two fold serial dilutions of each serum sample were prepared $(1,1: 2,1: 4,1: 8$, $1: 16,1: 32)$. Whole blood agglutination test was performed as described by Quinn et al. (2003).

Fecal swabs: Fifteen serologically positive birds were selected randomly and cloacal swabs were taken from them on the same day of blood collection. The swabs were pre-enriched in peptone water (incubated at $37^{\circ} \mathrm{C}$ for 48 hours) and then inoculated into $10 \mathrm{ml}$ of tetrathionate broth and incubated at $37^{\circ} \mathrm{C}$ for 24 hours. The loopful of tetrathionate broth was inoculated on artificial media (Brilliant Green).
Statistical analysis: MINITAB statistical software was used and binary logistic regression was the methodology adopted in data analysis.

\section{Results}

In this study, there was no significant difference observed between two antigens to detect carrier birds by whole blood agglutination test. Salmonella was not isolated from cloacal swabs since no observed excretion of Salmonella Pullorum through faces. All cloacal swabs gave negative results, when cultured on artificial Agar.

Table-1. Number of positive samples for each dilution level.

\begin{tabular}{lccccc}
\hline $\begin{array}{l}\text { Dilution } \\
\text { of serum }\end{array}$ & $\mathbf{1 : 2}$ & $\mathbf{1 : 4}$ & $\mathbf{1 : 8}$ & $\mathbf{1 : 1 6}$ & $\mathbf{1 : 3 2}$ \\
\hline A & 60 & 46 & 39 & 27 & 18 \\
B & 60 & 47 & 33 & 20 & 13 \\
\hline
\end{tabular}

(A-Local antigen, $\mathrm{B}$ - I mported branded antigen)

Since $P$ value was $0.092(P>0.05)$ of the test by Binary Logistic Regression there were no statistically significant different observed in both antigens.

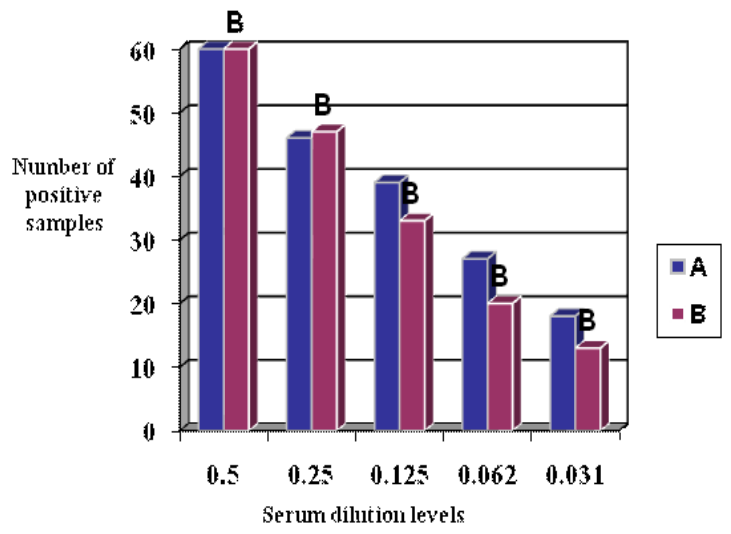

Figure-1. Number of positive samples against serum dilution levels.

All samples gave negative results and there was no any pink colony, when cultured on brilliant green agar. No Salmonella organsim was isolated from the cloacal swabs taken from serologically positive birds.

\section{Discussion}

In this study both antigen were detected antibodies in chicken infected with S. Pullorum. There was no significant difference between "A" and "B." The results were the same in diluted serum tested up to $1: 32$, since there is unique reading using both antigens, 
accuracy of the national control program would not affected by local antigen used. The testing was done in the room temperature to minimize the variables such as environment temperature, dust particles and quality of the blood used [1]. However, those factors were not negligible in the field level at mass screening. In this experiment relatively large doses were administered on the same day though this condition is not common in the field. The antibody titer can be varied with the different doses of exposure and other variable in immune system such as immune suppression by concurrent infection $[9,10]$. The serological detection of S. Pullorum infection in chicken may depend more on the immunogenic of the infecting strain than on the composition of the agglutination test antigen used [6]. However the basis of the immunogenic of S. Pullorum strains has not been clearly established [6].

All the negative results for fecal swabs and feaces of infected carrier birds were not uncommon in carrier birds. It was described that S.Pullorum is not a gut inhabitants [6] and not survive for longer time period although transmitted vertically $[6,10]$. Possibility of horizontal transmission at later ages was not investigated in this study. Also it was suggested with previous studies that horizontal transmission by the conventional fecal-oral route may not be very common route of excretion $[2,3]$.

\section{Conclusion}

Findings of the study concluded that there was no significant difference observed between local and branded imported antigen in detecting carrier birds of Pullorum by whole blood agglutination test. Both antigens were similarly effective as a screening test in Salmonella control program in poultry breeders.

\section{Author's contribution}

M.A.R.Priyantha is the Principle investigator of the study and physical work was done by the Priyani Medawewa,AA Vipulasiri, M.I.Wijemuni, N. Liyanagunawardana. GA Gunawardana supervised as the head of the Department. M.A.R.Priyantha drafted the manuscript and revised the manuscript. All authors read and approved the final manuscript.

\section{Acknowledgements}

Authors would like to acknowledge all the staff at Bacteriology division who helped to complete this research activity, also the research committee at Faculty of Veterinary Medicine and Animal science, Director/VRI and Director General of DAP\&H for granting permission to carry out the research, finally the staff at both Karandhagolla and Marawilla NLDB farm.

\section{Competing interest}

Authors declares that they have no competing interest.

\section{References}

1. Quinn,P.J., Markey,B.K., Carter,M.E., Donelly, W.J., (2003)Veterinary Microbiology and Microbial disease, Blackwell science Ltd., Blackwell publishing company,UK.

2. Gast,R.K.,(1997) Detecting infections of chickens with recent Salmonella pullorum isolates using Standard serological methods. Poultry Science.Vol 76, pp 17-23.

3. Gast,R.K.,(2003) Salmonella Infections.In: Diseases of poultry 11th ed. Iowa state press,Blackwell publishing company,UK. pp 575-578.

4. Kabir,S.M.L.,(2010).Avian Colibacillosis and Salmonellosis:A Closer look at Epidemiology, pathogenesis, diagnosis,control and pulic health Concerns. Int.J.Envion.res.Public Health.,7,89-114.

5. OIE (2008) Manual of Diagnostic Tests and Vaccines for TerrestrialAnimals $6^{\text {th }}$ Edition. Vol $1 \& 2$.

6. Calenge, F., Kaiser, P.,Vignal, A., and C. Beaumont (2010). Genetic control of resitance to Salmonellosis and to Salmonella carrier-state in fowl: a review. Genetics Selection Evolution,42: 11.

7. Priyantha M.A.R.,Vipulasiri,A.A., G.A. Gunawardana (2012).Salmonella control in poultry breeder farms in Sri lanka: Effect of oral antibiotic treatment on WBAT with Salmonella Pullrom antigen.IJLP,Vol.3(2),2124.

8. Priyantha M. A. R. (2009). An Overview: Vaccination to control fowl typhoid in commercial layers, Sri Lanka. Wayamba Journal of Animal Science, ejournal. Num.1261469976.,Date:22/12/2009.

9. Grimes,T.M.,Simmons,G.C.,(1972) Non specific reactions to rapid whole blood Salmonella pullorum antigens,Australian Veterinary Journal, 48, 609-610.

10. Berchieri,A.Jr.,Murphy,C.K.,Marston,K.andP.A. Barrow (2001),Observation on the persistence and vertical transmission of Salmonella enteric serovars Pullorum and Gallinarum in chickens: effect of bacterial and host gnetic background. Avian Pathology. 30: 221-231.

$$
* * * * * * * *
$$

